\title{
Propriedades óticas e microestruturais de filmes finos eletrodepositados de CdTe
}

\author{
Optical and Microstructural Properties of Electrodeposited \\ CdTe Thin Films
}

Cruz, L.R. ${ }^{1}$; San Miguel, Q.G.S. ${ }^{2}$

\author{
${ }^{1}$ Laboratório de Filmes Finos, Instituto Militar de Engenharia, 22290-270, Rio de Janeiro, RJ., Brasil \\ e-mail: leilacruz@,ime.eb.br \\ ${ }^{2}$ Laboratório de Espectroscopia Mössbauer, Universidad Nacional Mayor de San Marcos \\ CP 140149, Lima, 14, Peru. \\ e-mail: quiricossm@hotmail.com
}

\section{RESUMO}

Filmes finos de CdTe foram obtidos por eletrodeposição catódica, a partir de uma solução de $\mathrm{CdSO}_{4}, \mathrm{H}_{2} \mathrm{SO}_{4}$ e Te. Os filmes foram depositados à temperatura ambiente, sobre substratos de vidro cobertos com $\mathrm{SnO}_{2}$ ou $\mathrm{In}_{2} \mathrm{O}_{3}: \mathrm{Sn}$. A influência do potencial de deposição nas propriedades microestruturais e óticas dos filmes foi investigada. Os valores de banda proibida dos filmes ficaram na faixa de 1,40 e 1,50 eV, próximos ao valor da banda do CdTe volumétrico. Um potencial de deposição ótimo foi determinado para cada substrato. $\mathrm{O}$ aquecimento do eletrólito a $50{ }^{\circ} \mathrm{C}$ não foi suficiente para provocar grandes alterações na cristalinidade, mas promoveu a formação de filmes com menor quantidade de defeitos. Isto sugere que um tratamento térmico pós-deposição possa melhorar as propriedades destes filmes para aplicações fotovoltaicas.

Palavras-chave: Microestrutura, Filmes finos de CdTe, eletrodeposição

\begin{abstract}
CdTe thin films were obtained by cathodic electrodeposition from a solution of $\mathrm{CdSO}_{4}, \mathrm{H}_{2} \mathrm{SO}_{4}$, and Te. The films were deposited at room temperature onto glass substrates covered with $\mathrm{SnO}_{2}$ or $\operatorname{In}_{2} \mathrm{O}_{3}: \mathrm{Sn}$. The dependence of the microstructural and optical properties of the films on deposition potential was investigated. The bandgap values ranged from 1.4 to $1.5 \mathrm{eV}$, as in bulk CdTe. An optimum value for the deposition potential was determined for each substrate. Heating the electrolyte to $50^{\circ} \mathrm{C}$ did not change the film crystallinity, although it decreased the defect concentration. This suggests that a post-deposition heat treatment may lead to a better performance of the films in photovoltaic devices.
\end{abstract}

Keywords: Microstructure, CdTe thin film, electrodeposition

\section{INTRODUÇÃO}

Filmes finos de CdTe compõem a camada absorvedora de células solares de CdS/CdTe. Atualmente, várias empresas produzem módulos de filmes finos de $\mathrm{CdS} / \mathrm{CdTe}$, disputando o mercado fotovoltaico com os módulos de silício cristalino, os quais respondem por $85-90 \%$ da produção global [1]. O destaque é para a First Solar, líder mundial na produção de módulos fotovoltaicos, que atingiu em 2011 a marca de $2 \mathrm{GWp}$, somente com a tecnologia de filme fino de CdTe [2]. Para efeitos de comparação, a Suntech Power, segunda maior fabricante, produziu no mesmo ano 1,9 GWp de módulos de silício cristalino [3]. O grande desafio destas empresas é diminuir ainda mais os custos de produção dos módulos, os quais, em 2011, giravam em torno de US\$ 0.75/Wp, para os de filmes finos de CdTe [2], e US\$ 1.25/Wp, para os de silício cristalino [4]. 
Diminuir custos na produção passa necessariamente por implantar processos baratos e adequados para fabricação em grandes volumes.

Os filmes finos de CdTe podem ser fabricados por diversas técnicas [5-7], dentre elas a eletrodeposição [8-14], uma técnica de baixo custo quando comparada aos demais processos de crescimento de filmes. Além disso, a técnica não exige equipamentos de vácuo, não envolve altas temperaturas e é facilmente adaptada para produção em larga escala. Nesta técnica, o CdTe é depositado em um cátodo a partir de uma solução ácida de um sal de cádmio, por exemplo $\mathrm{CdSO}_{4}$, e $\mathrm{TeO}_{2}$. O processo de deposição no cátodo é descrito pelas seguintes reações [8, 14]:

$$
\begin{array}{ll}
\mathrm{HTeO}_{2}^{+}+3 \mathrm{H}^{+}+4 \mathrm{e}^{-} \rightarrow \mathrm{Te}+2 \mathrm{H}_{2} \mathrm{O}, & E_{o}=+0,551 \mathrm{~V} \\
\mathrm{Cd}^{2+}+\mathrm{Te}+2 \mathrm{e}^{-} \rightarrow \mathrm{CdTe}, & E_{o}=-0,403 \mathrm{~V}
\end{array}
$$

onde $E_{o}$ é o potencial de eletrodo de equilíbrio em relação ao hidrogênio [14]. Devido à diferença elevada entre os potenciais de redução das duas espécies, faz-se necessário usar um eletrólito com alta concentração de $\mathrm{Cd}^{2+}$ e baixa concentração da espécie mais positiva $\mathrm{HTeO}_{2}{ }^{+}$, de forma a garantir a estequiometria do filme [8, 14]. É possível atender a este requisito para o $\mathrm{Cd}$, que está em excesso na solução. No caso dos íons de Te, como a concentração deve ser mantida baixa $\left(10^{-4}-10^{-5} \mathrm{M}\right)$, deve-se adotar formas de mantê-la constante durante a deposição. Uma delas é utilizar dois anodos, um de telúrio e outro de grafite, alternados por meio de uma chave eletrônica [8]. Assim, os íons são repostos durante toda a deposição. A taxa de crescimento do filme é controlada pela disponibilidade e pelo transporte de $\mathrm{HTeO}_{2}{ }^{+}$, cuja concentração na interface eletrodo-eletrólito é extremamente baixa. A composição, a estrutura e a natureza da condutividade do semicondutor de CdTe são muito dependentes dos parâmetros de deposição, tais como a temperatura da solução e o potencial de deposição. Em potenciais negativos baixos, filmes do tipo p são obtidos, pois possuem excesso de Te. Em potenciais negativos elevados uma camada n é obtida, devido ao excesso de $\mathrm{Cd}[8,11]$. Importante ressaltar que a condutividade do CdTe é controlada essencialmente pelo desvio de sua estequiometria, pois a dopagem com impurezas aceitadoras ou doadoras é extremamente difícil, devido ao efeito de autocompensação [15]. Isto significa que é energeticamente mais favorável os dopantes formarem complexos de defeitos, ou defeitos eletricamente ativos, do que substituírem os átomos da rede do CdTe [16]. Assim, a condutividade neste semicondutor está associada ao excesso de Te (tipo $p$ ) ou de $\mathrm{Cd}$ (tipo $n$ ), o que somente pode ser obtido em uma faixa muito estreita de composição, de acordo com o diagrama de fases do sistema Cd-Te [15]. Isto explica o fato de a camada de CdTe-p utilizada nas células ser, em geral, muito resistiva. No entanto, esta desvantagem é mais do que compensada pelas excelentes propriedades de absorção deste semicondutor no espectro visível [17].

Este trabalho descreve as propriedades microestruturais e óticas de filmes de CdTe eletrodepositados a partir de uma solução aquosa de sulfato de cádmio, sob diferentes potenciais de deposição.

\section{MATERIAIS E MÉTODOS}

\subsection{A célula eletroquímica e eletrodos}

A célula eletroquímica era constituída de um conjunto de eletrodos imersos em um eletrólito contido em um béquer, onde uma reação de oxidação-redução ocorria ao se aplicar uma diferença de potencial. Ao todo, cinco eletrodos foram utilizados:

i) dois ânodos, sendo um inerte (grafite) e outro de telúrio (Te), atuando, respectivamente, como auxiliar, completando o circuito da célula eletrolítica, e fonte de íons de Te (IV); este arranjo permitiu repor a quantidade de íons $\mathrm{HTeO}_{2}^{+}$no eletrólito;

ii) um cátodo (eletrodo de trabalho), substrato condutor onde se produziam as reações eletroquímicas de redução; o fluxo de corrente no eletrólito ocorria entre o eletrodo de trabalho e o eletrodo auxiliar;

iii) um eletrodo extra de grafite, utilizado como cátodo para separar a redução de CdTe no substrato da introdução de íons $\mathrm{HTeO}_{2}^{+}$no eletrólito;

iv) um eletrodo de referência de $\mathrm{Ag} / \mathrm{AgCl}$, empregado para medir o potencial do eletrodo de trabalho.

Como eletrodos de trabalho, foram utilizados substratos de vidro sodalime, de $1 \times 1 \mathrm{pol}^{2}$, cobertos com dois tipos de filmes condutores: óxido de índio-estanho (ITO), depositados por pulverização catódica [18], e 
óxido de estanho dopado com flúor $\left(\mathrm{SnO}_{2}: \mathrm{F}\right)$, adquiridos da empresa Flexitec. Ambos os substratos possuíam resistência de folha na faixa de $10-20 \Omega / \square$.

\subsection{O procedimento de deposição}

O eletrólito consistia de uma solução aquosa de sulfato de cádmio $\left(\mathrm{CdSO}_{4}\right)$, grau analítico, de $0,33 \mathrm{~mol} / \mathrm{dm}^{3}$ [8]. O pH foi controlado pela adição de ácido sulfúrico na solução e mantido entre 1,7-2,0. Um agitador magnético foi colocado na solução com uma rotação de $200 \mathrm{rpm}$. Os eletrodos foram então introduzidos e o potencial de deposição (potencial entre o eletrodo de referência e o de trabalho) foi ajustado para o valor desejado. O potencial de oxidação (potencial entre o eletrodo de referência e o de telúrio) foi fixado em 500 $\mathrm{mV}$, valor obtido consultando-se o diagrama de Pourbaix, que mostra que, para valores de $\mathrm{pH}$ em torno 2, o potencial que favorece a oxidação do $\mathrm{Te}$ a íons $\mathrm{HTeO}^{+}{ }_{2}$ encontra-se acima de $500 \mathrm{mV}$ [10]. A deposição ocorria alternando-se a aplicação de potencial entre o eletrodo de telúrio e o inerte. Isto foi feito por meio de um sistema de chaveamento eletrônico. Quando a corrente passava pelo ânodo de Te, injetava-se $\mathrm{HTeO}_{2}^{+}$na solução. Quando a corrente passava pelo ânodo inerte, o Te era consumido no cátodo formando o CdTe. Para obter uma quantidade de $\mathrm{HTeO}^{+}{ }_{2}$ no eletrólito na faixa de $10^{-5} \mathrm{~mol} / \mathrm{dm}^{3}[8]$, utilizou-se um tempo de $8 \mathrm{~s}$ para a oxidação, valor obtido da lei de Faraday [19], a qual relaciona a massa liberada pelo eletrodo com a corrente aplicada, no caso $0,5 \mathrm{~mA}$. Para a redução, o tempo foi de $16 \mathrm{~s}$, pois a corrente que circulava no catodo era $0,25 \mathrm{~mA}$. Neste trabalho, filmes de CdTe com espessuras entre 0,1 e $0,4 \mu \mathrm{m}$ foram crescidos à temperatura ambiente e a $50{ }^{\circ} \mathrm{C}$, com potencial de deposição variando entre $-250 \mathrm{mV}$ e $-700 \mathrm{mV}$. Esta faixa foi selecionada a partir de curvas de voltametria obtidas na literatura, que mostram que a deposição do CdTe ocorre em potenciais de catodo situados entre $-200 \mathrm{mV}$ e $-650 \mathrm{mV}$, em relação a um eletrodo de referência $\mathrm{Ag} / \mathrm{AgCl}$ [8]. A diferença de voltagem entre o eletrodo de referência e o eletrodo de trabalho era controlada por um potenciômetro desenvolvido especialmente para este fim, mediante medida do fluxo de corrente entre o eletrodo de trabalho e o auxiliar. O parâmetro controlado era o potencial da célula e o parâmetro de controle era a corrente da cuba eletrolítica, o que permitia manter constante o potencial de trabalho da célula. $\mathrm{O}$ tempo total de deposição foi fixado em $1 \mathrm{~h}$.

\subsection{Caracterização dos filmes}

A estrutura dos filmes e as fases presentes foram investigadas por difração de raios X (DRX). A análise foi realizada no modo Bragg-Brentano, nos difratômetros MINIFLEX RIGAKU e SIEMENS modelo D5000, com radiação $\mathrm{K} \alpha$ do cobre. A morfologia e a composição dos filmes foram avaliadas em um microscópio eletrônico de varredura (MEV), marca JEOL, modelo JSM - 5800LV, com acessório de espectroscopia por dispersão de energia (EDS), modelo MP-84071, da Noran. A microscopia de força atômica (MFA) foi feita em um microscópio da Topometrix Accurex II. A espessura dos filmes foi medida por perfilometria em um rugosímetro, marca VEECO Dektak. A caracterização ótica dos filmes foi feita em um espectrofotômetro da Varian, modelo CARY 5, com feixe duplo, empregando como referência o substrato de vidro coberto com ITO ou $\mathrm{SnO}_{2}$.

\section{RESULTADOS E DISCUSSÃO}

A Figura 1 mostra os padrões de DRX dos filmes depositados sobre substratos vidro/ $\mathrm{SnO}_{2}: \mathrm{F}$ em diferentes potenciais. Todos os picos pertencentes ao substrato e ao CdTe estão assinalados. Em $-250 \mathrm{mV}$, verificam-se dois picos de difração do CdTe de baixa intensidade, (111) e (311), sugerindo que o filme é nanocristalino. Sob potencial de $-300 \mathrm{mV}$, o filme se deposita na forma cristalina do CdTe, que tem estrutura do tipo blenda do zinco [15]. As difrações mais intensas do CdTe estão identificadas com os respectivos planos. O parâmetro de rede, obtido pelo método de extrapolação linear [20], é 6,48 Å e está de acordo com o valor reportado para o cristal de CdTe (base de dados JCPDS 15-770). Uma comparação dos padrões mostrados na Figura 1 com o padrão do JCPDS do pó permitiu concluir que o filme depositado a $-300 \mathrm{mV}$ cresceu com orientação preferencial na direção [111], resultado também observado por outros autores [12]. O crescimento preferencial nesta direção é típico de filmes de CdTe crescidos à temperatura ambiente, devido a ser este o plano de mais baixa energia superficial nesta estrutura. Em temperaturas elevadas, o crescimento orientado geralmente é comprometido, dando lugar a uma distribuição aleatória de grãos [6]. Efeito semelhante ocorreu em relação ao potencial de deposição. Em baixos potenciais, geralmente tem-se baixa energia conferida às espécies, consequentemente, a microestrutura mais estável foi a orientada, com os planos de mais baixa energia paralelos à superfície. Potenciais mais negativos que $-300 \mathrm{mV}$ provavelmente proporcionaram 
energias muito elevadas, o que favoreceu a perda da orientação e da cristalinidade dos filmes. Ainda que cristalinos, os filmes depositados a $-300 \mathrm{mV}$ possuem uma grande quantidade de defeitos e microdeformações, o que pode ser confirmado pela grande largura à meia altura dos picos. O recozimento dos filmes deve ser considerado para promover uma redução nestes defeitos.

Os padrões de DRX de filmes depositados sobre substratos vidro/ITO em diferentes potenciais são mostrados na Figura 2. Os picos pertencentes ao substrato e ao CdTe estão assinalados. Observa-se que, também para os filmes depositados sobre ITO, existe um potencial de deposição ótimo, a partir do qual estes filmes perdem orientação e cristalinidade. Na Figura 2, este potencial é $-400 \mathrm{mV}$, potencial no qual os filmes são cristalinos e fortemente orientados na direção [111]. Como os substratos usados nesta série foram diferentes dos utilizados na série da Figura 1, era de fato esperado que o potencial ótimo não fosse o mesmo, uma vez que as propriedades microestruturais de filmes finos, em geral, dependem fortemente do substrato. No entanto, a cristalinidade dos filmes foi maior quando estes foram depositados sobre ITO. Este fato pode estar relacionado com as diferentes condutividades e/ou rugosidades dos substratos. No difratograma da amostra depositada a $-400 \mathrm{mV}$ aparecem três picos de baixa intensidade, provavelmente devido a óxidos. Eles não são provenientes de telúrio livre, como no caso da amostra depositada a $-650 \mathrm{mV}$.
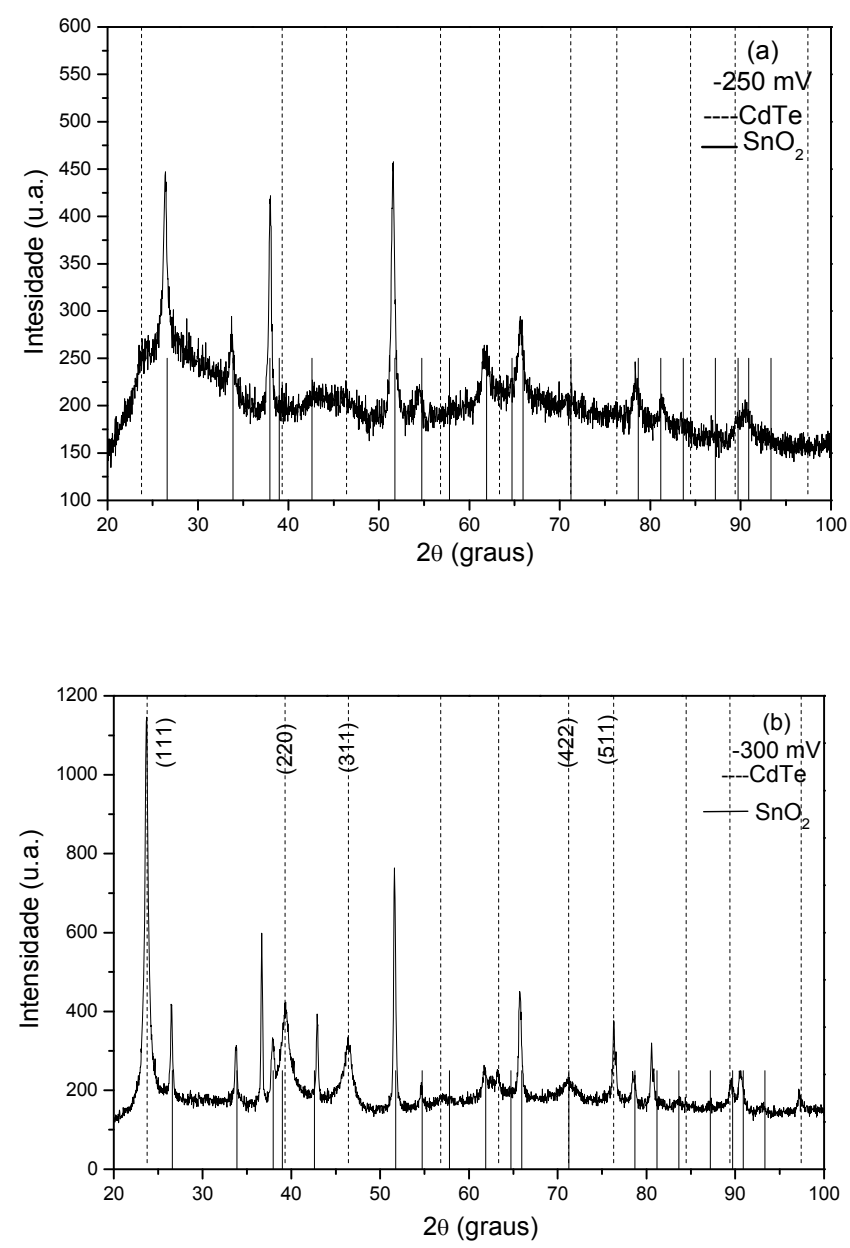

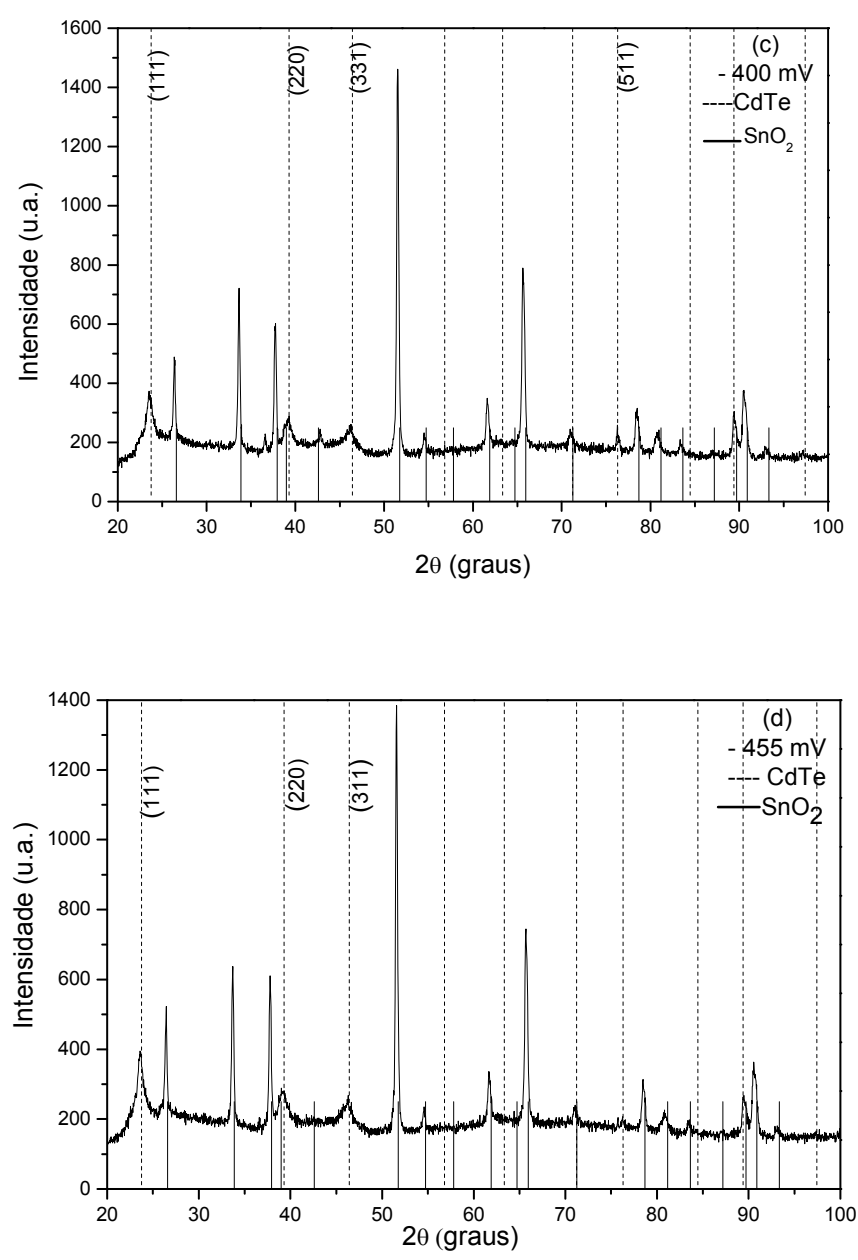

Figura 1: Padrões de DRX de filmes de $\mathrm{CdTe} / \mathrm{SnO}_{2}$ depositados sob diferentes potenciais em relação à referência $\mathrm{Ag} / \mathrm{AgCl}$.

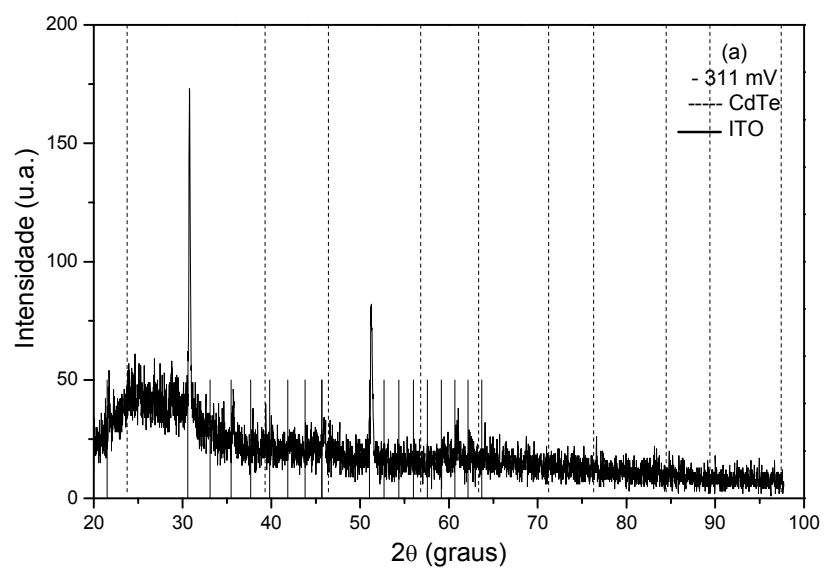



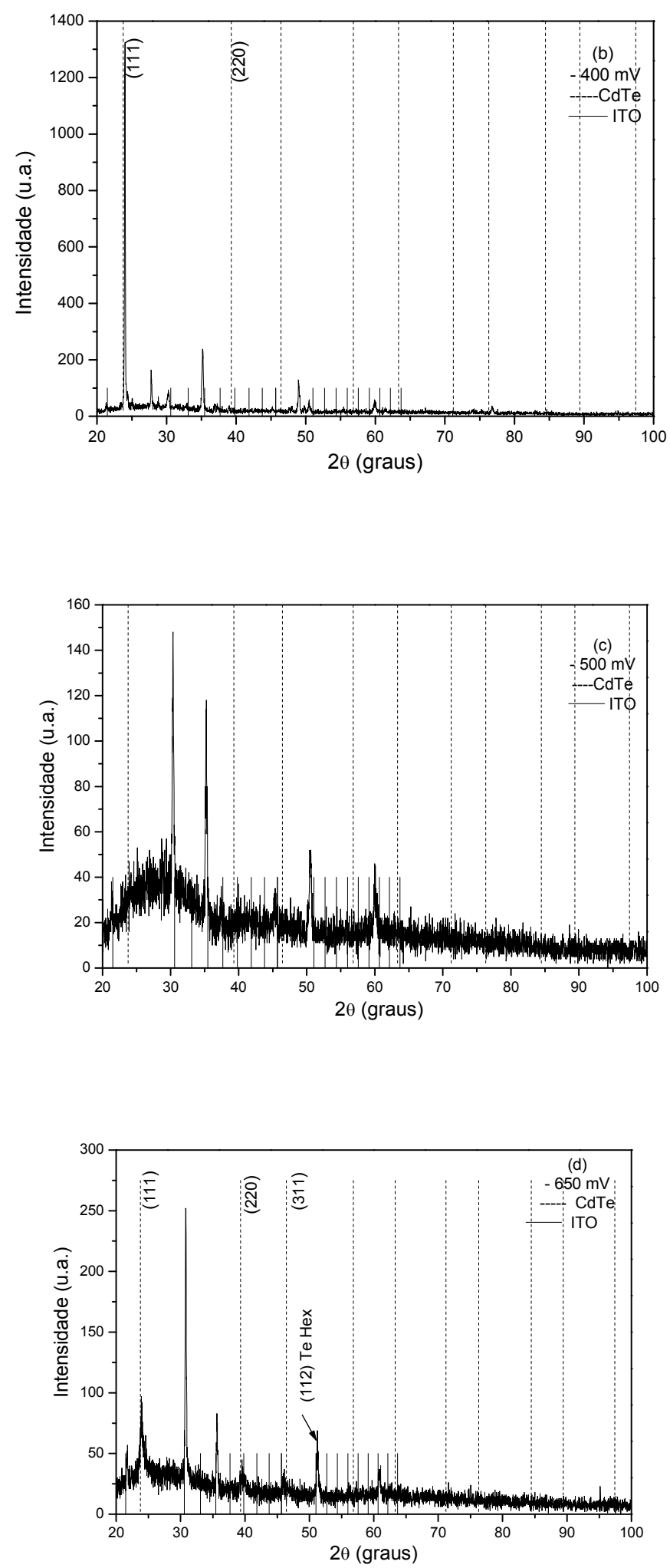

Figura 2: Padrões de DRX de filmes de CdTe/ITO depositados sob diferentes potenciais em relação à referência $\mathrm{Ag} / \mathrm{AgCl}$.

As análises seguintes, que visavam avaliar a aplicabilidade do CdTe em células fotovoltaicas, foram realizadas somente nos filmes depositados sobre ITO, pois estes apresentaram maior cristalinidade. 
A Figura 3 mostra as imagens de MFA obtidas das amostras depositadas sobre vidro/ITO em diferentes potenciais. O tamanho médio de grão ficou na faixa de dezenas de nanômetros, conforme mostrado na Tabela 1. Filmes de CdTe com grãos nanométricos não são adequados para atuarem na célula solar como absorvedores da radiação, devido à elevada densidade de contornos de grãos, os quais agem como centros de recombinação dos portadores de carga fotogerados [17].

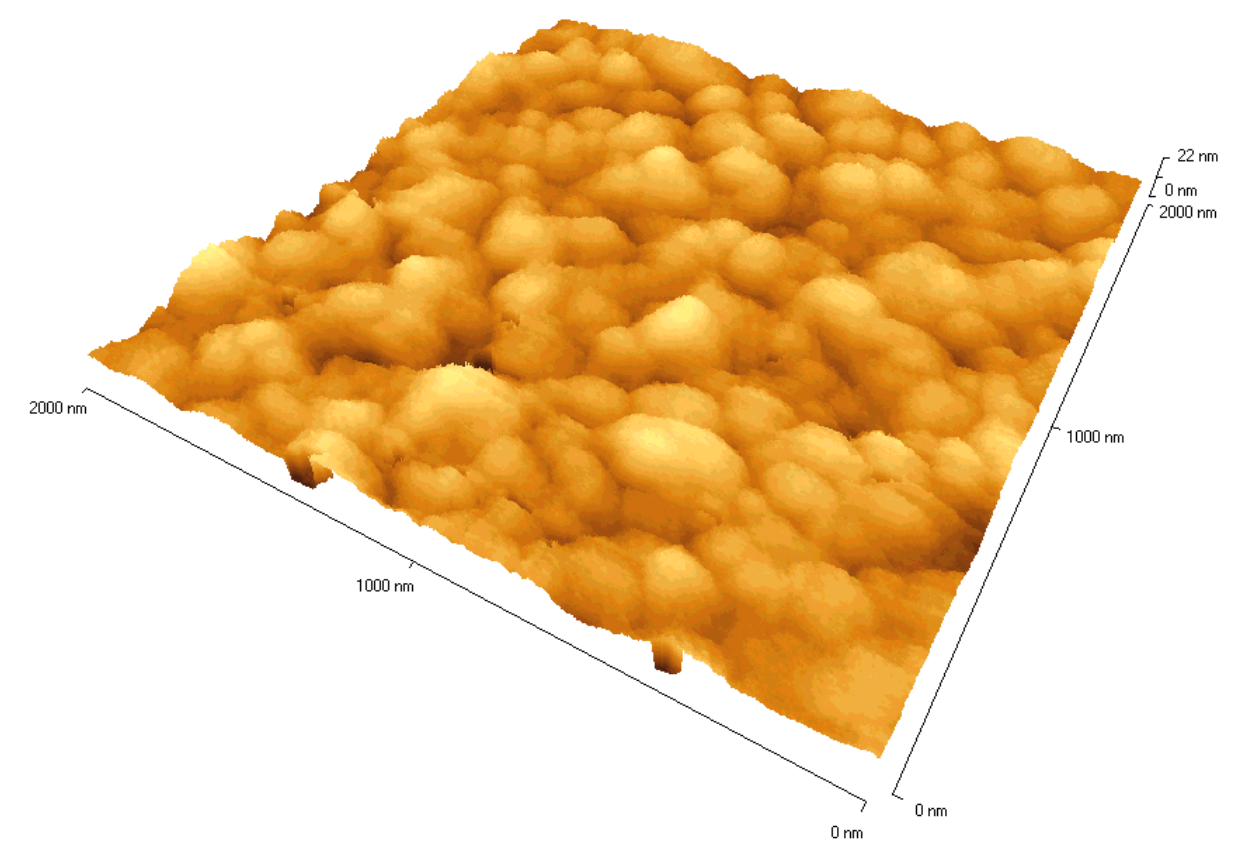

(a)

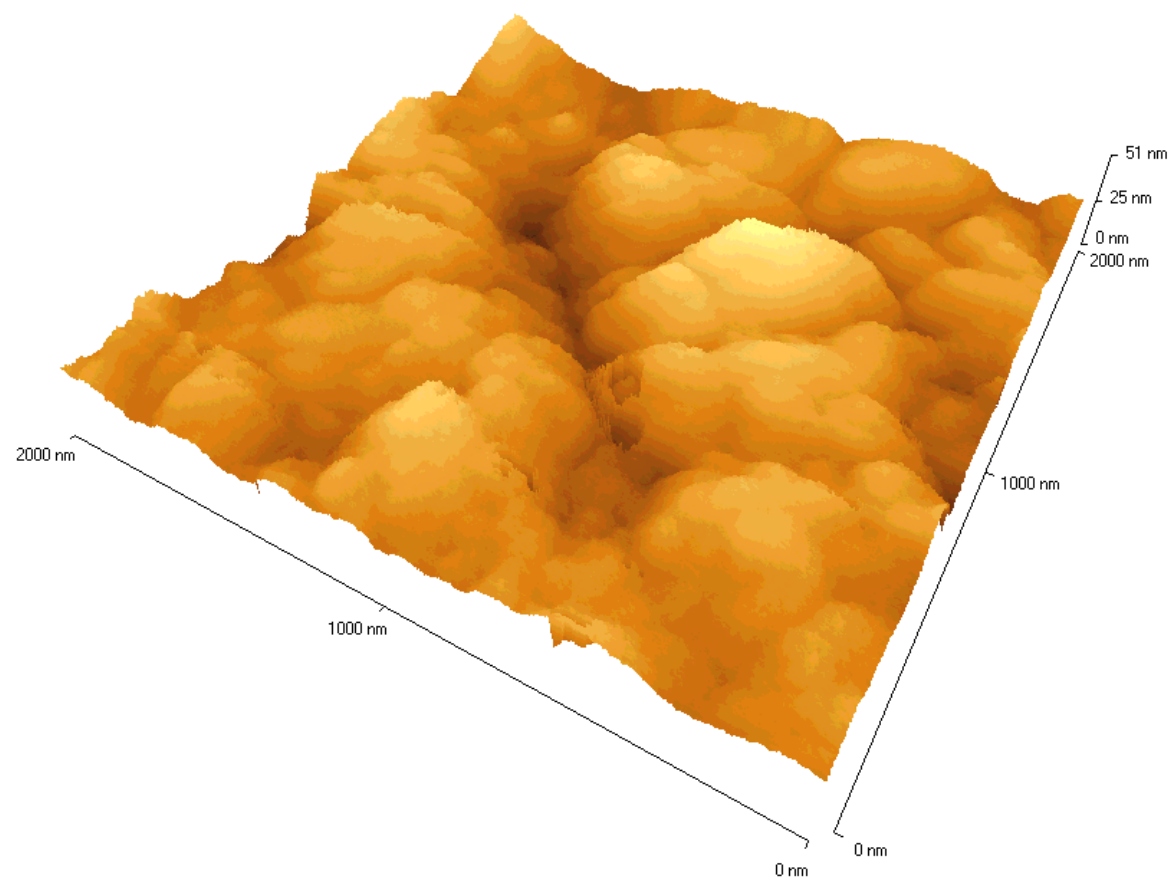

(b) 


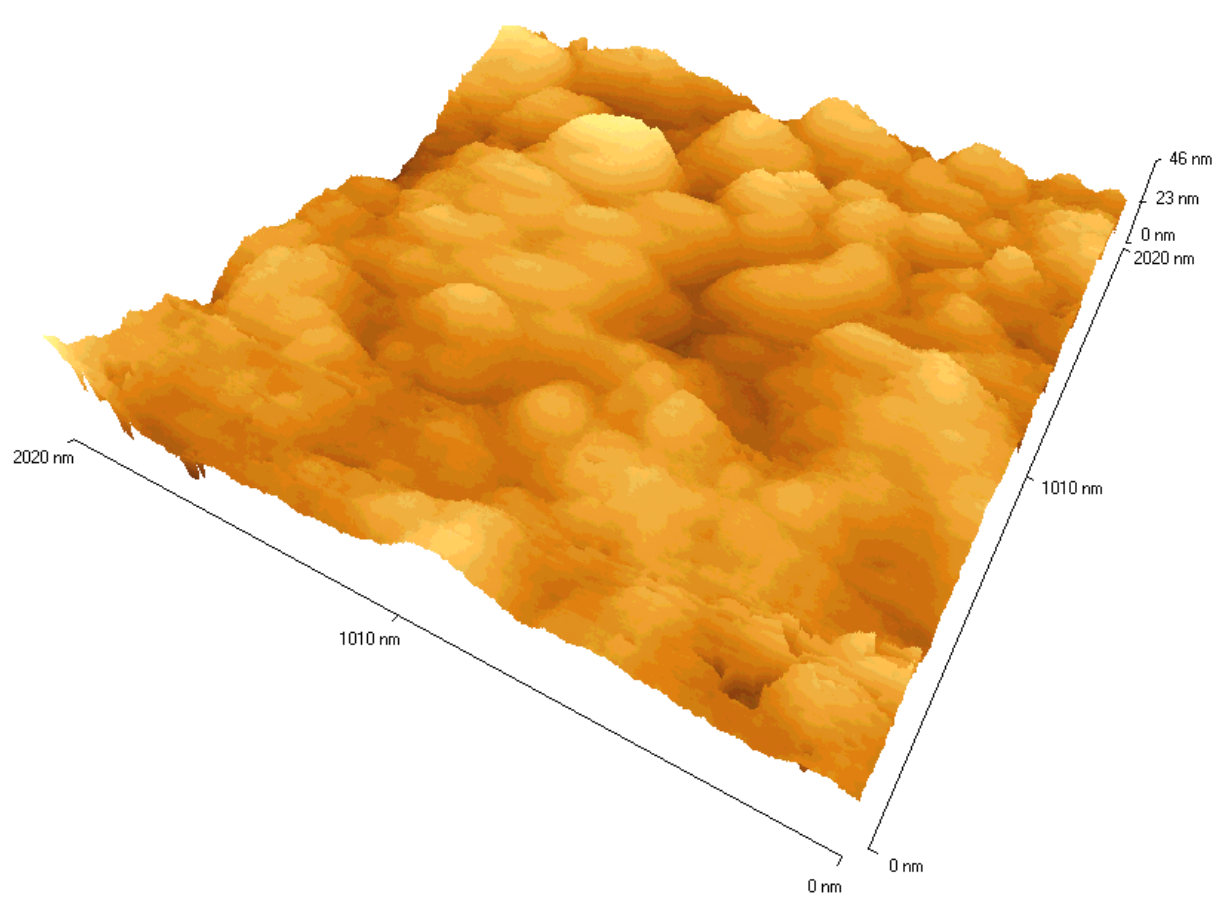

(c)

Figura 3: Imagens de MFA de filmes de CdTe/ITO depositados sob diferentes potenciais em relação à referência $\mathrm{Ag} / \mathrm{AgCl}$ : (a) $-300 \mathrm{mV}$; (b) $-400 \mathrm{mV}$; (c) $-500 \mathrm{mV}$.

Tabela 1: Propriedades de filmes de CdTe/ITO depositados sob diferentes potenciais

\begin{tabular}{l|c|c|c|c|c}
\hline $\begin{array}{c}\text { AMOSTRAS POTENCIAL } \\
\text { DE DEPOSIÇÃO }(\mathbf{m V})\end{array}$ & $\begin{array}{c}\text { ESPESSURA } \\
\mathbf{( s / n m )}\end{array}$ & $\begin{array}{c}\text { TAXA DE } \\
\text { DEPOSIÇÃO } \\
\mathbf{( s / m m})\end{array}$ & \%atCd/\%atTe & $\begin{array}{c}\text { TAMANHO DE } \\
\text { GRÃO }(\mathbf{n m})\end{array}$ & $\begin{array}{c}\text { BANDA } \\
\text { PROIBIDA (eV) }\end{array}$ \\
\hline $\mathrm{CdTe} / \mathrm{ITO}-311$ & 1075 & 17,9 & $8 / 92$ & 60 & -- \\
\hline $\mathrm{CdTe} / \mathrm{ITO}-400$ & 1170 & 19,5 & $33 / 64$ & 45 & 1,49 \\
\hline $\mathrm{CdTe} / \mathrm{TTO}-500$ & 1365 & 22,8 & $27 / 73$ & 25 & 1,41 \\
\hline $\mathrm{CdTe} / \mathrm{TTO}-600$ & 1655 & 27,6 & $33 / 67$ & 35 & 1,52 \\
\hline $\mathrm{CdTe} / \mathrm{ITO}-600-50^{\circ} \mathrm{C}$ & 1985 & 33,1 & $32 / 68$ & 45 & 1,43 \\
\hline
\end{tabular}

O coeficiente de absorção ótica $(\alpha)$ dos filmes de CdTe foi obtido a partir dos espectros de transmitância e refletância, utilizando-se a Equação 3, na qual $t$ é a espessura do filme, $T_{f, s}$ é a transmitância do conjunto filme/substrato, $T_{s}$ é a transmitância do substrato, $R_{f, s}$ é a refletância do conjunto filme/substrato e $R_{s}$ é a refletância do substrato [21]. A energia da banda proibida dos filmes foi obtida a partir dos valores de $\alpha$ e com o auxílio da Equação 4, onde $c$ é uma constante, $h v$ é a energia do fóton e $E_{g}$ é o valor da banda proibida [17]. Um gráfico de $\alpha^{2}$ em função de $h v$ forneceu o valor de $E_{g}$ na interseção com o eixo $\alpha^{2}=0$, conforme ilustrado na Figura 4 para o filme depositado sobre vidro/ITO a $-400 \mathrm{mV}$.

$$
\begin{aligned}
& \alpha=-\frac{1}{t} \ln \frac{T_{f, s}\left(1-R_{s}\right)}{T_{s}\left(1-R_{f, s}\right)} \\
& (h v \alpha)^{2}=c\left(h v-E_{g}\right)
\end{aligned}
$$


$\mathrm{Na}$ Figura 4, observa-se uma pequena transição indireta em torno de $0,9 \mathrm{eV}$, transição esta que apareceu em diversos espectros de absorção e que pode estar associada tanto à fase não identificada no difratograma da Figura $2 \mathrm{~b}$ quanto a uma fase de Te livre.

A Tabela 1 também mostra a composição e a banda proibida dos filmes depositados sobre ITO com diferentes potenciais de deposição. Observa-se que o aumento no potencial de deposição levou a maiores taxas de deposição, devido ao incremento da corrente durante o processo de transferência de cargas na eletrólise. Os filmes cresceram ricos em telúrio, cujo percentual diminuiu para maiores potenciais de deposição, conforme também relatado na literatura [12]. Sabe-se que o excesso de telúrio contribui para a condutividade tipo $\mathrm{p}$ [15]. No entanto, o percentual de telúrio mostrado na Tabela 1 é demasiadamente elevado para estar relacionado apenas com a presença de vacâncias de cádmio no CdTe. Isto sugere a presença de uma fase livre de Te, o que pode ser constatado na Figura 2d. Esta nova fase não está presente em todos os difratogramas da Figura 2, provavelmente por ser amorfa. De fato, este excesso de Te não poderia estar relacionado totalmente a um desvio na estequiometria no CdTe, visto que o CdTe é um composto; o próprio diagrama de equilíbrio do sistema Cd-Te apresenta um campo muito estreito para variações de composição em torno da composição estequiométrica $\mathrm{Cd}: \mathrm{Te}=1: 1$ [15]. Os valores de banda proibida situaram-se entre 1,41 e 1,52 eV, próximos de 1,50 eV, valor da banda do cristal de CdTe [17]. Observa-se que a banda proibida do filme com composição mais próxima à estequiométrica, aquele crescido a $-400 \mathrm{mV}$, é praticamente igual à do cristal de CdTe. Os filmes depositados a $-311 \mathrm{mV}$ e $-700 \mathrm{mV}$ não apresentaram a aresta de absorção típica do CdTe.

Dado que a microestrutura dos filmes depositados à temperatura ambiente era muito deformada e composta de grãos nanométricos, optou-se por aquecer a solução a $50^{\circ} \mathrm{C}$. Os resultados para a amostra crescida a $-600 \mathrm{mV}\left(\mathrm{CdTe} / \mathrm{ITO}-600-50^{\circ} \mathrm{C}\right)$ estão mostrados na Tabela 1. A taxa de deposição aumentou com a temperatura da solução, de acordo com o que é esperado para processos termicamente ativados. Por outro lado, a composição não foi influenciada pela temperatura do eletrólito. Também não se verificaram mudanças significativas na cristalinidade dos filmes, conforme ilustrado na Figura 5. No entanto, a temperatura contribuiu para reduzir os defeitos no interior da banda do CdTe. Isto pode ser constatado na Figura 6, que mostra a aresta de absorção fundamental bem mais abrupta e definida nos filmes crescidos a $50{ }^{\circ} \mathrm{C}$. Isto sugere que um tratamento térmico pós-deposição possa melhorar significativamente as propriedades destes filmes. Uma microestrutura com baixa densidade de defeitos e com grãos grandes é fundamental para que a absorção de radiação e a separação de cargas sejam eficientes nos dispositivos à base de CdTe [17].

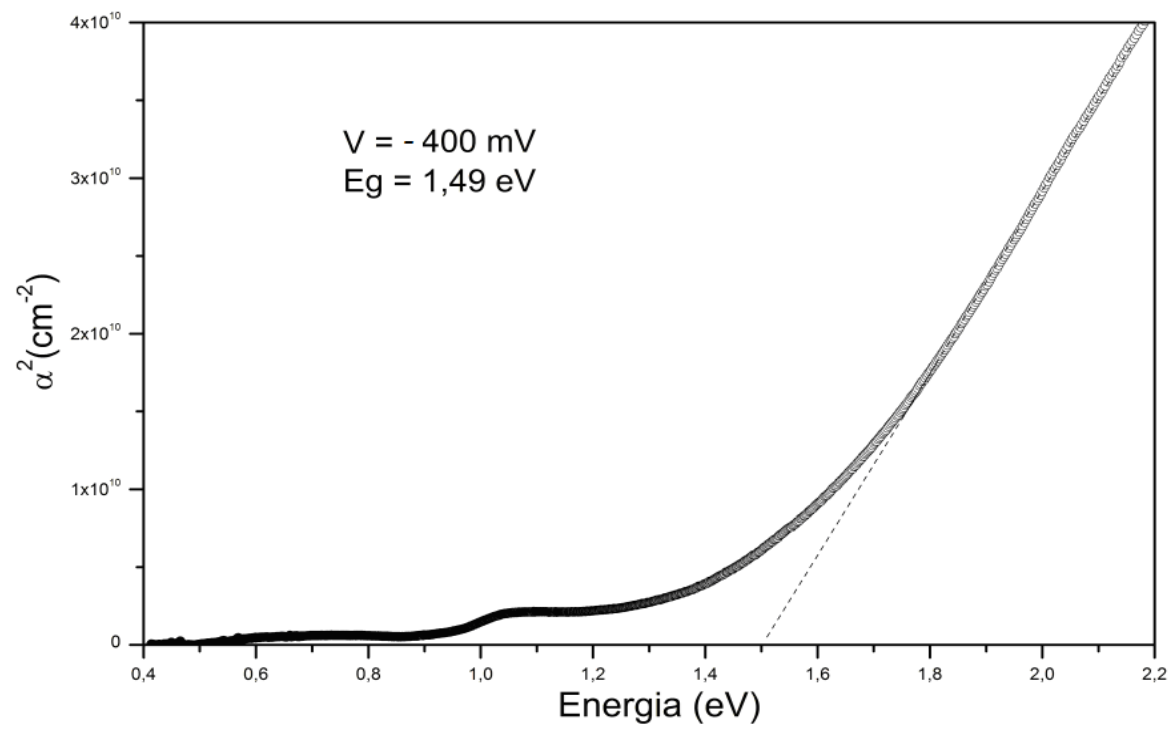

Figura 4: Coeficiente de absorção do filme de CdTe/ITO em função da energia do fóton: obtenção da banda proibida 

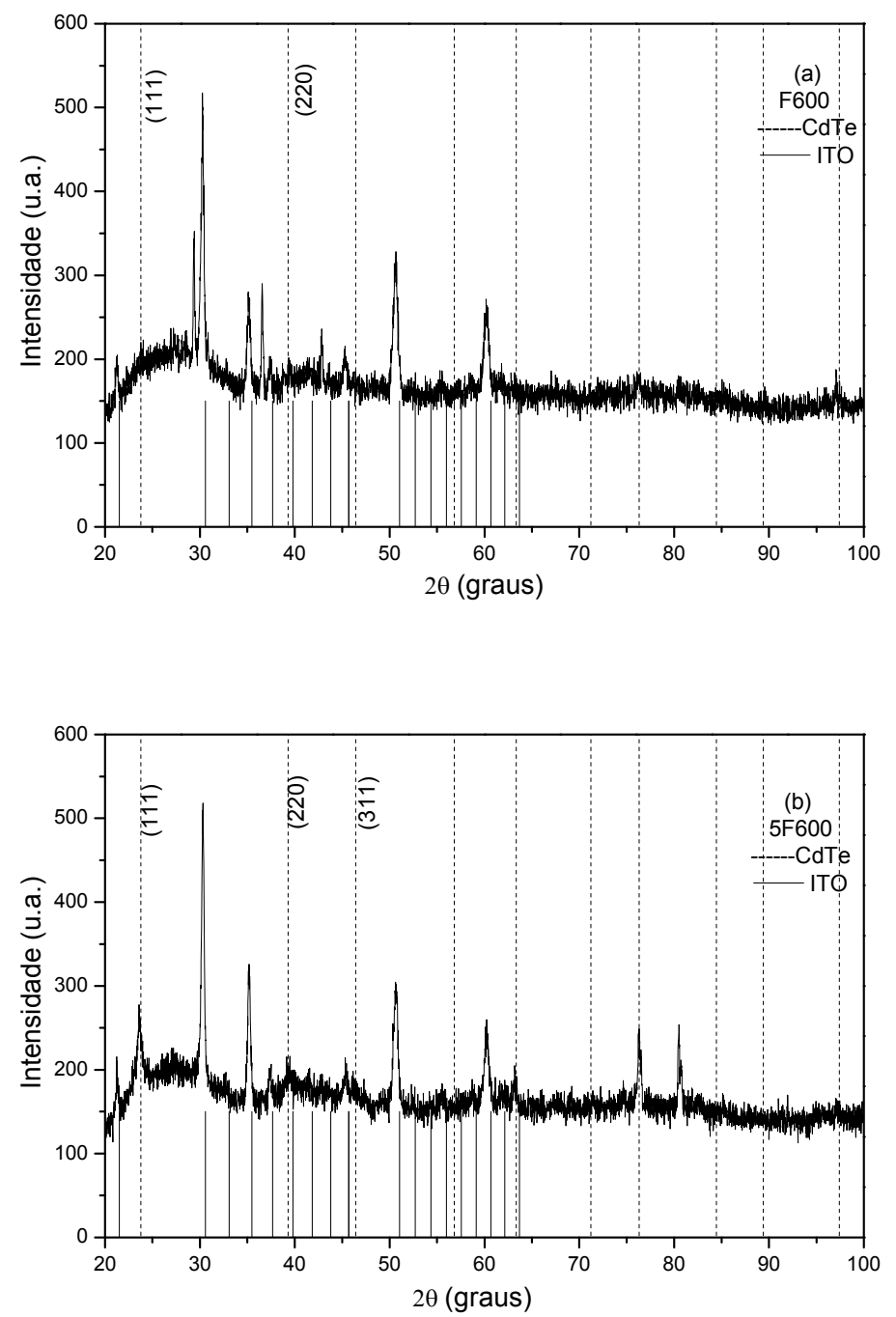

Figura 5: Padrões de DRX de filmes de $\mathrm{CdTe} / \mathrm{ITO}$ depositados sob potencial de $-600 \mathrm{mV}$ em relação à referência $\mathrm{Ag} / \mathrm{AgCl}$ nas temperaturas: (a) ambiente; (b) $50^{\circ} \mathrm{C}$.

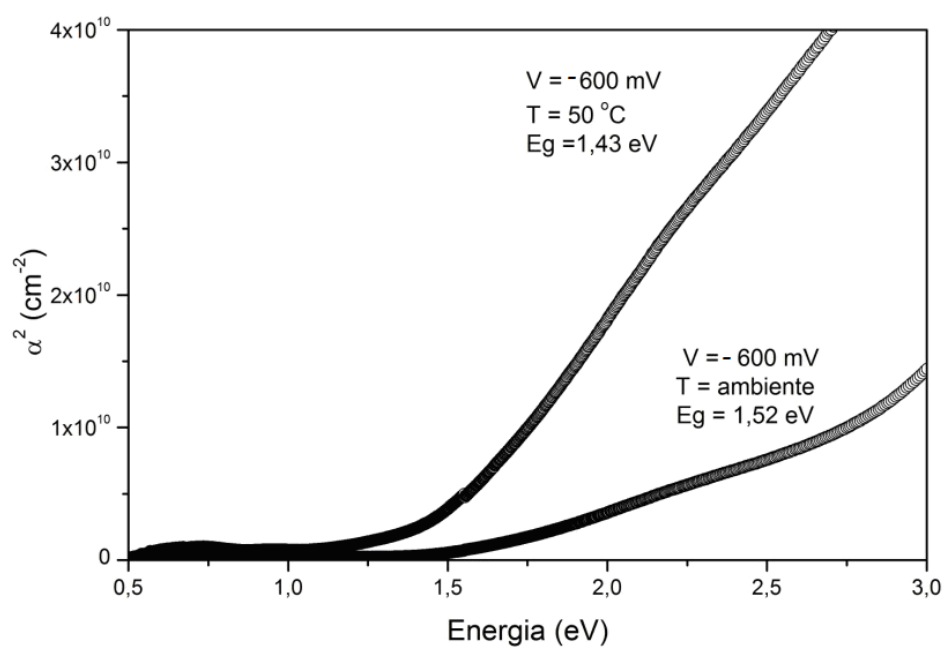

Figura 6: Coeficiente de absorção de filmes de CdTe/ITO em função da energia do fóton. 
A microestrutura nanocristalina e com defeitos obtida neste trabalho é típica de filmes de CdTe depositados em baixas temperaturas, pois a sua estrutura cristalina, a esfalerita (blenda de zinco), favorece a incorporação de defeitos em baixas temperaturas [15]. De qualquer forma, o tratamento térmico do CdTe é uma etapa que jamais é descartada no processamento industrial do dispositivo, dada a sua importância na obtenção de células eficientes. Este tratamento é feito em presença de um fundente, $\mathrm{CdCl}_{2}$, que tem o papel de ativar os processos difusionais, tais como crescimento de grão e recuperação de defeitos [6]. Desta forma, antes de serem utilizados em células solares, os filmes obtidos a $-400 \mathrm{mV}$ devem ser submetidos a este tratamento. Neste caso, filmes de CdS, que compõem a camada $n$ da junção, deverão ser crescidos sobre os substratos cobertos com ITO antes da deposição do CdTe.

\section{CONCLUSÕES}

Filmes finos de CdTe foram crescidos por eletrodeposição sobre substratos condutores transparentes em diferentes potenciais de deposição. Os filmes obtidos eram ricos em Te, indicando que a condutividade era do tipo p. Os melhores filmes foram depositados sobre substratos de vidro cobertos com ITO sob potencial de $-400 \mathrm{mV}$ em relação à referência $\mathrm{Ag} / \mathrm{AgCl}$. Os valores encontrados para o parâmetro de rede e a banda proibida foram semelhantes aos do cristal de CdTe. A microestrutura nanocristalina dos filmes obtidos sugere que os mesmos devam ser submetidos a tratamento térmico, antes de serem utilizados como camada absorvedora em células solares. Os resultados deste trabalho podem contribuir para um estudo mais amplo, no qual toda a célula solar, com configuração vidro/ITO/CdS/CdTe/contato, seja fabricada por eletrodeposição.

\section{AGRADECIMENTOS}

Este trabalho foi financiado pelo Departamento de Ciência e Tecnologia (DCT) do Exército Brasileiro, através de verba orçamentária, e pelo Conselho Nacional de Desenvolvimento Científico e Tecnológico (CNPq), Edital Universal 472255/01-0.

\section{BIBLIOGRAFIA}

[1] Solarbuzz, disponível em: http://www.solarbuzz.com. Acessado em abril de 2012.

[2] Optics.Org, disponível em: http://optics.org/news/3/4/21. Acessado em abril de 2012.

[3] Sustainable Business, disponível em:

http://www.sustainablebusiness.com/index.cfm/go/news.display/id/23506. Acessado em abril de 2012.

[4] MEHTA, S., PV Technology, Production and Cost Outlook: 2010-2015, disponível em:

http://www.gtmresearch.com/report/pv-technology-production-and-cost-outlook-2010-2015. Acessado em abril de 2012.

[5] BOSIO, A., ROMEO, N., MAZZAMUTO, S., et al., "Polycrystalline CdTe thin films for photovoltaic applications", Progress in Crystal Growth and Characterization of Materials, v. 52, pp. 247-279, Dec. 2006.

[6] QUADROS, J., PINTO, A.L., MOUTINHO, H.R., et al., "Microtexture of chloride treated CdTe thin films deposited by CSS technique", Journal of Materials Science, v. 43, pp. 573-579, Jan. 2008.

[7] SESTAK, M.N., LI, J., CHEN, J., et al., "Effects of as-deposited CdTe microstructure on solar cell performance", In: Proceedings of the 35th Photovoltaic Specialists Conference, pp. 873-877, Honolulu, Hi, Nov. 2010.

[8] BASOL, B.M., "Electrodeposited CdTe and HgCdTe solar cells", Solar Cells, v. 23, pp. 69-88, Feb. 1988.

[9] KOKATE, A.V., ASABE, M.R., HANKARE, P.P., et al., "Effect of annealing on properties of electrochemically deposited CdTe thin films", Journal of Physics and Chemistry of Solids, v. 68, pp. 53-58, Jan. 2007.

[10] SELLA, C., BONCORPS, P., VEDEL, J., "The electrodeposition mechanism of CdTe from acidic aqueous solutions", Journal of the Electrochemical Society, v. 133, n. 10, pp. 2043-2047, Oct. 1986.

[11] MAMEDOV, M.N., ALIEV, A.S., "Electrical properties of electrodeposited CdTe thin films", Inorganic Materials, v. 44, no. 8, pp. 804-806, 2008. 
[12] SOLIMAN, M., KASHYOUT, A.B., SHABANA, M., et al., "Preparation and characterization of thin films of electrodeposited CdTe semiconductors", Renewable Energy, v. 23, pp. 471-481, 2001.

[13] DUTTA, J., BHATTACHARYYA, D., MAITI, A.B., et al., "Studies of grain boundary effect in electrodeposited cadmium telluride films from optical measurements", Vacuum, v. 46, no.1, pp.17-22, 1995.

[14] PANICKER, M.P.R, KNASTER, M., KROGER, F.A., "Cathodic deposition of CdTe from aqueous electrolytes", Journal Electrochemical Society, v. 125, pp. 566-572, 1978.

[15] ZANIO, N., Cadmium telluride, In: Willardson, R.K., Beer, A.C. (eds), Semiconductors and Semimetals, v. 13, New York, USA, Academic Press, 1978.

[16] WEI, S.-H., ZHANG, S.B., "Theoretical study of doping limits of CdTe”, In: NCPV Program Review Meeting, Lakewood, Colorado, October 2001.

[17] FAHRENBRUCH, A.L., BUBE, R.H., Fundamentals of solar cells, 1 ed., New York, Academic Press, 1983.

[18] CRUZ, L.R., LEGNANI, C., MATTOSO, I.G., et al., "Influence of pressure and annealing on the microstructural and electro-optical properties of magnetron sputtered ITO thin films", Materials Research Bulletin, v. 39, no. 7/8, pp. 993-1003, 2004.

[19] ADAMIAN, R., ALMENDRA, E., Físico-Química - Uma aplicação aos materiais, Rio de Janeiro, COPPE/UFRJ, 2002.

[20] CULLITY, B.D., Elements of X-Ray Diffraction, 2 ed., Boston, Addison-Wesley Publishing Company, 1978.

[21] PANKOVE, J.I., Optical Process in Semiconductors, 1 ed., New York, Dover Publications, 1971. 